\title{
In vitro anti-acetylcholinesterase activity of an aqueous extract of Unicaria tomentosa and in silico study of its active constituents
}

\author{
Suman Chowdhury, Shivani, Suresh Kumar*
}

University School of Biotechnology, Guru Gobind Singh Indraprastha University, Dwarka, New Delhi; Suresh Kumar - Email: sureshkumar@ipu.ac.in; *Corresponding author

Received March 22, 2016; Accepted March 30, 2016; Published June 15, 2016

\begin{abstract}
:
Depletion of acetylcholine in the central nervous system (CNS) is responsible for memory loss and cognition deficit. Enzyme acetylcholinesterase $(\mathrm{AChE})$ is responsible for destruction of acetylcholine (Ach) in the brain. Many herbal plant extracts have been investigated for their potential use in the treatment of Alzheimer's disease (AD) by inhibiting AChE and upregulating the levels of Ach. The current study investigated the anti-acetylcholinesterase (AChE) activity of an aqueous extract of Unicaria tomentosa bark which has not been reported so far in the literature. The in vitro study of an aqueous extract of $U$. tomentosa showed maximum inhibition of $76.2 \pm 0.002 \%$ at $0.4 \mathrm{mg} / \mathrm{ml}$ of final concentration with an $\mathrm{IC}_{50}=0.112 \mathrm{mg} / \mathrm{ml}$. The mechanism of inhibition was elucidated by kinetic study which showed mixed type of inhibition, this might be due to the presence of various phytoconstituents such as oxindole alkaloids present in an aqueous extract. Based on molecular structure of phytoconstituents obtained from $U$. tomentosa known from the relevant literature, in-silico molecular docking study was performed against AChE protein to validate the results.
\end{abstract}

Keywords: Anti-cholinesterase, Acetylcholinesterase, Unicaria tomentosa, Ellman's assay, Enzyme Kinetics, Lineweaver-Burk plot, Oxindole alkaloids, Molecular docking, Schrodinger.

Background:

Alzheimer's disease (AD) is a neurodegenerative disease and the most common form of dementia afflicting approximately 35 million people worldwide [1]. AD is an acquired, progressive illness with gradual deterioration of central nervous system until death. One in ten persons over 65 and nearly half of adults over 85 years have AD [2]. The clinical symptoms associated with $\mathrm{AD}$ include impaired ability to learn new information and recall old information, a decline in language function, dyspraxia, agnosia and impairment of executive functioning [3]. Neuropathological changes include neuronal reduction, neurofibrillary tangles, senile neurotic plaques and a variable amyloid angiopathy [4]. Neurochemical changes occur, including a marked reduction in the levels of acetylcholine and other neurotransmitters and neuromodulators [5]. Several mechanisms have been proposed to explain the cause of the disease including those of the misfolded and aggregated proteins of amyloid beta and tau [6]. But, the most conventional theory is "cholinergic hypothesis". This hypothesis proposes that there is decline in concentration of the neurotransmitter, acetylcholine (Ach) mainly due to the action of cholinesterase enzymes in CNS [7, 8]. Therefore, the current therapeutic strategies mainly involve focusing on anti-cholinesterase inhibitors.

There are limited therapeutic options available for AD. The available drugs in the market for symptomatic treatment have several drawbacks such as side effects, low bioavailability, high cost and requirement of weekly blood monitoring [9]. In view of these limitations, the present study focuses on an aqueous extract of Uncaria tomentosa, commonly known as cat's claw for AChE inhibition activity. U. tomentosa is a large, woody vine that is indigenous to the Amazon rainforest [10]. U. tomentosa bark has been used traditionally in Peruvian medicine to treat gastritis, asthma and arthritis inflammatory conditions [11]. The herb has also been shown to possess antioxidant properties 
[12]. In-vivo and in-vitro work has also shown that $U$. tomentosa extract alone and in combination with at least one of Ginkgo biloba, rosemary, gotu kola and bacopin, prevent the formation beta-amyloid plaques and the extract alone improves memory function in mice with experimental amnesia [13-14]. Of particular interest is the significant binding of an oxindole alkaloid (mitraphylline) with beta-amyloid 1-40 [15]. Number of biologically active compounds such as quinovic acid glycosides, triterpenes, flavonoids (rutin and quercetin), phytosteroids (b-sitosterol, stigmasterol, and campesterol), and catechins are present in different parts of the plant. Out of these compounds, the most pharmacologically active compounds are tetracyclic oxindole such as rhyncophylline and isorhyncophylline and pentacyclic oxindole such as speciophylline, uncarine $\mathrm{F}$, uncarine $\mathrm{C}$, uncarine $\mathrm{E}$, mitraphylline, isomitraphylline, pteropodine, and isopteropodine [16, 17]. The present study investigates in-vitro anti-AChE activity of an aqueous extract of $U$. tomentosa and insilico molecular docking study of active tetra-and pentacyclic oxindole constituents, to investigate the binding interactions with acetylcholinesterase enzyme.

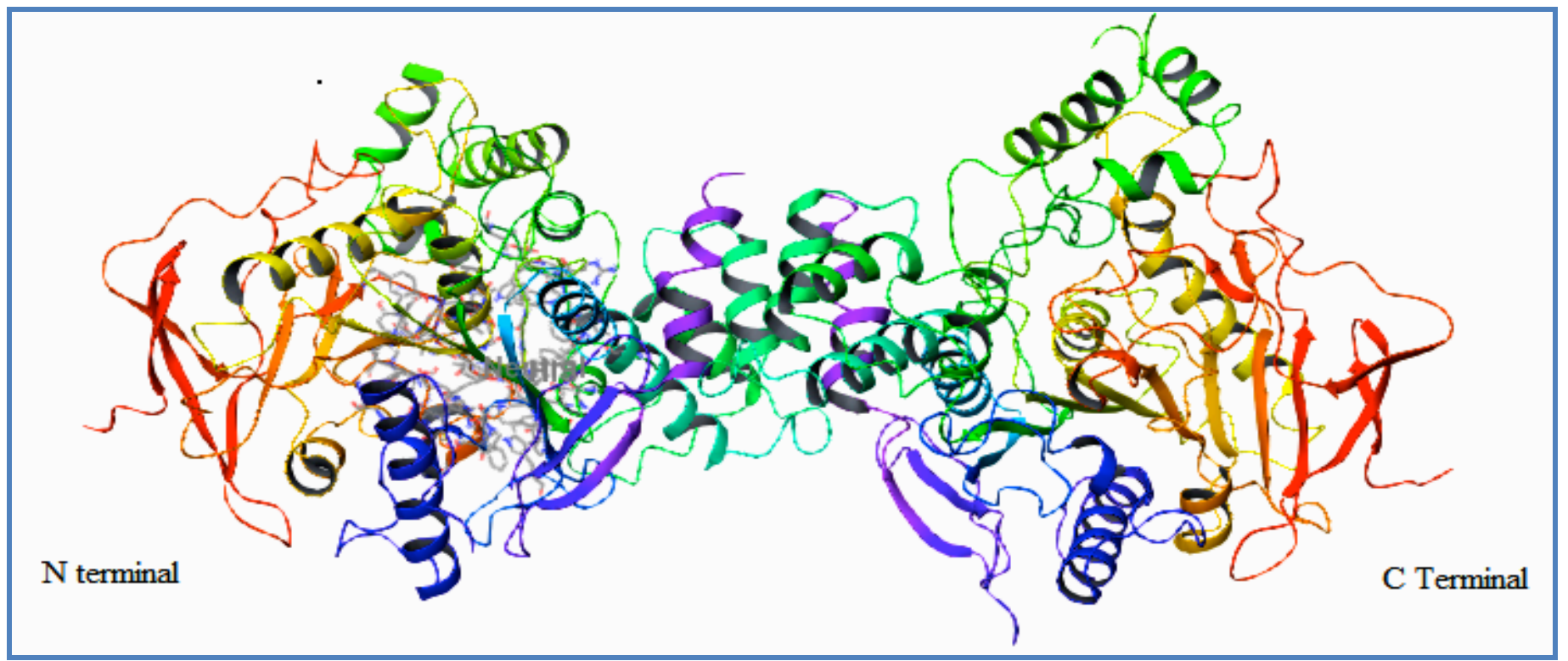

Figure 1: Three-dimensional structure of human acetyl-cholinesterase enzyme (PDBID 4EY6)

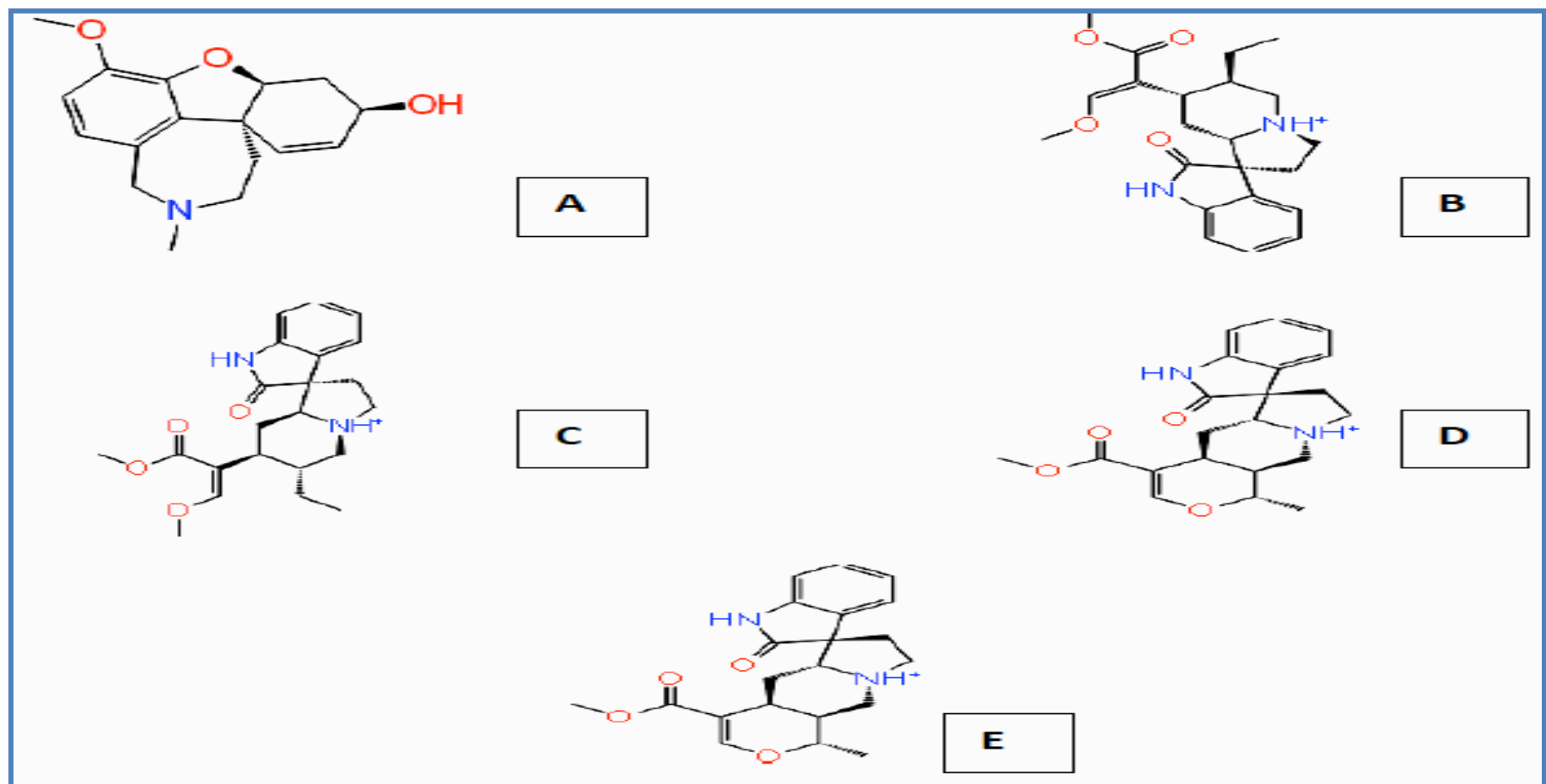

Figure 2: Two-dimension structure of A-Galantamine, B-Rhyncophylline, C-Isorhyncophylline, D-Unicarine E, E-Tacrine

ISSN 0973-2063 (online) 0973-8894 (print)

\section{BIOMEDICAL}

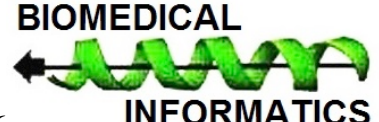




\section{Methodology:}

\section{Plant material and extraction}

The bark of $U$. tomentosa was purchased from a local store in Delhi, India and authenticated by a local botanist and a voucher specimen (USBT/SK/CC011) was stored in the herbarium at University School of Biotechnology, GGSIP University, Dwarka
Sec-16C, New Delhi-110075. Aqueous extracts was prepared by boiling $10 \mathrm{gm}$ of air dried bark powdered of herb in $50 \mathrm{ml}(1: 5$ $\mathrm{w} / \mathrm{v}$ ) of boiling distilled water for half an hour, from which freeze dried extracts were prepared using lyophilizer (Heto, Thermo scientific) and subsequently diluted in water to the desired concentrations.

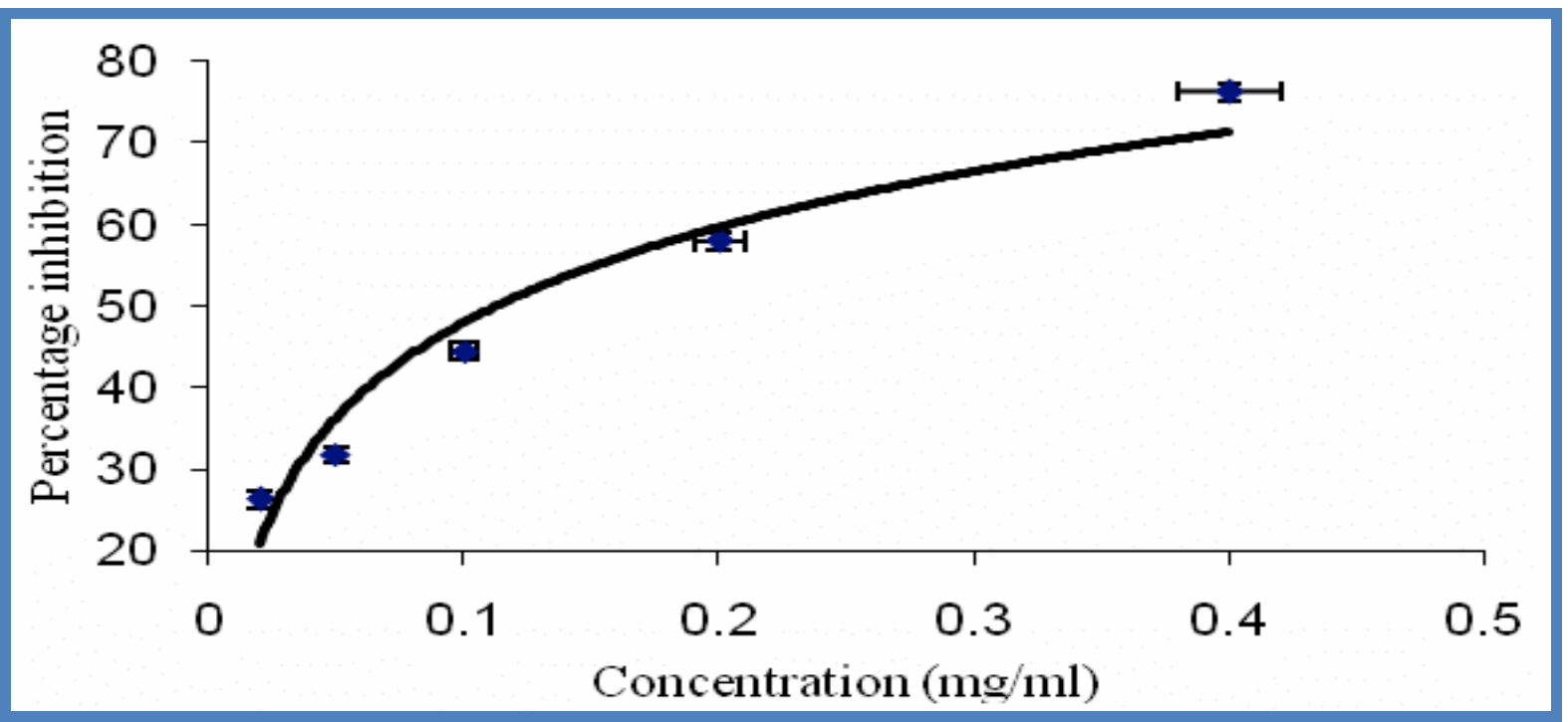

Figure 3: Concentration dependent enzyme inhibition activity (\%) against different concentration of $U$. tomentosa aqueous extract. $\left(y=16.873 \ln (x)+86.885, R^{2}=0.9458\right)$

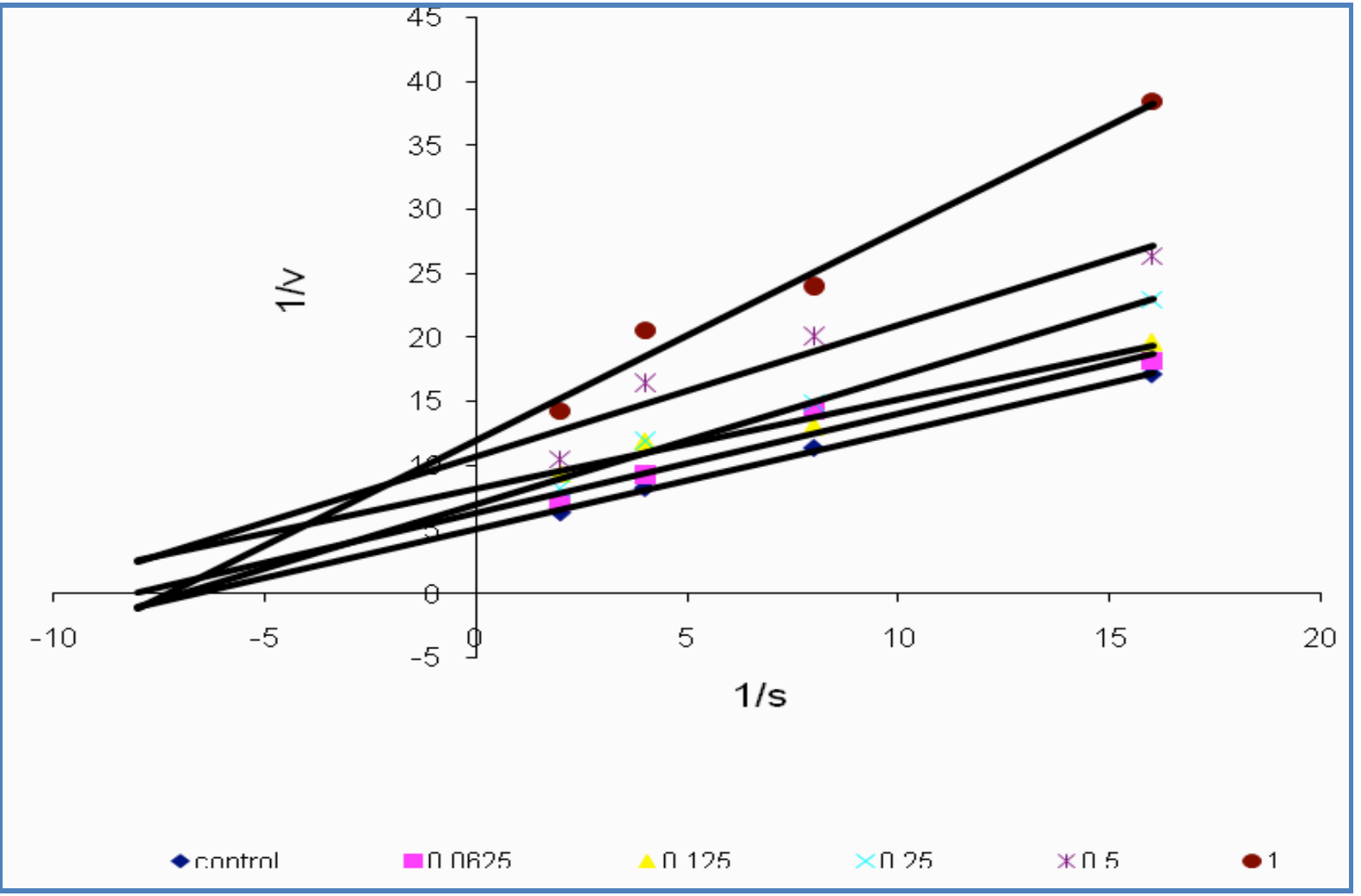

Figure 4: Line weaver-Burk plot of initial velocity of AChE against ATCh concentrations for control and different concentrations of U. tomentosa. 


\section{In-vitro assay}

The aqueous extract of $U$. tomentosa was examined for AChE inhibitory activity using Ellman's assay [18] at various concentrations $(0.4-0.025 \mathrm{mg} / \mathrm{ml})$ and was dissolved in a $0.1 \mathrm{M}$ phosphate buffer, $\mathrm{pH} 8$. To a flat bottom 96-well plate, typical run consisted of, $5 \mu \mathrm{l}$ of Acetylthiocholine (ATCh) $(0.5 \mathrm{mM}), 5$ $\mu \mathrm{l}$ of 5, 5'-dithiobis-2-nitrobenzoic acid (DTNB) $(0.03 \mathrm{mM})$ and $5 \mu \mathrm{l}$ of the test extract solution at the different concentrations evaluated, which were mixed and incubated for $10 \mathrm{~min}$ at 30 $\mu \mathrm{C}$. Then, $5 \mu \mathrm{l}$ of $\mathrm{AChE}(0.3 \mathrm{U} / \mathrm{ml})$ solution was added to the initial mixture to start the reaction and then absorbance was determined at 412nm (SpectraMax M2, 96-well plate reader). A control run contained all the aforementioned constituents with exception of the test extract. All experiments were performed in triplicate with two replicates. The concentration of the tested extract that inhibited the hydrolysis of substrate ATCh by $50 \%$ $\left(\mathrm{IC}_{50}\right)$ was determined by linear regression analysis. Kinetic analysis was also performed using Line weaver Burk method, where enzyme AChE was pre-incubated with different ATCh concentration ranging from $0.5-0.0625 \mathrm{mM}$ in the presence and absence (control) of different concentration of $U$. tomentosa ranging from $1-0.0625 \mathrm{mg} / \mathrm{ml}$.

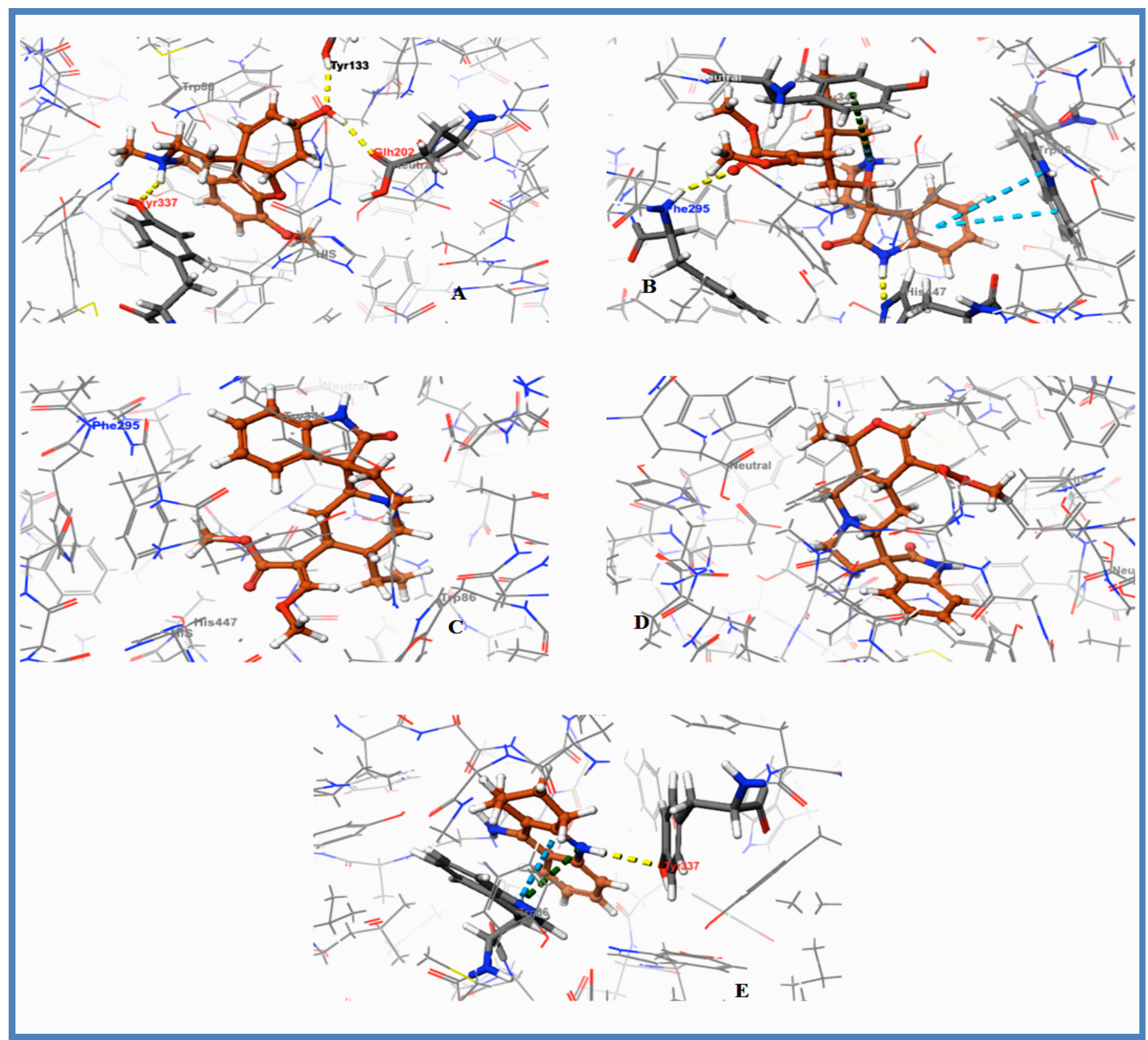

Figure 5: Binding mode between AChE enzyme and different ligand (A-Galantamine, B-Rhyncophylline, C-Isorhyncophylline, DUnicarine E, E-Tacrine). 

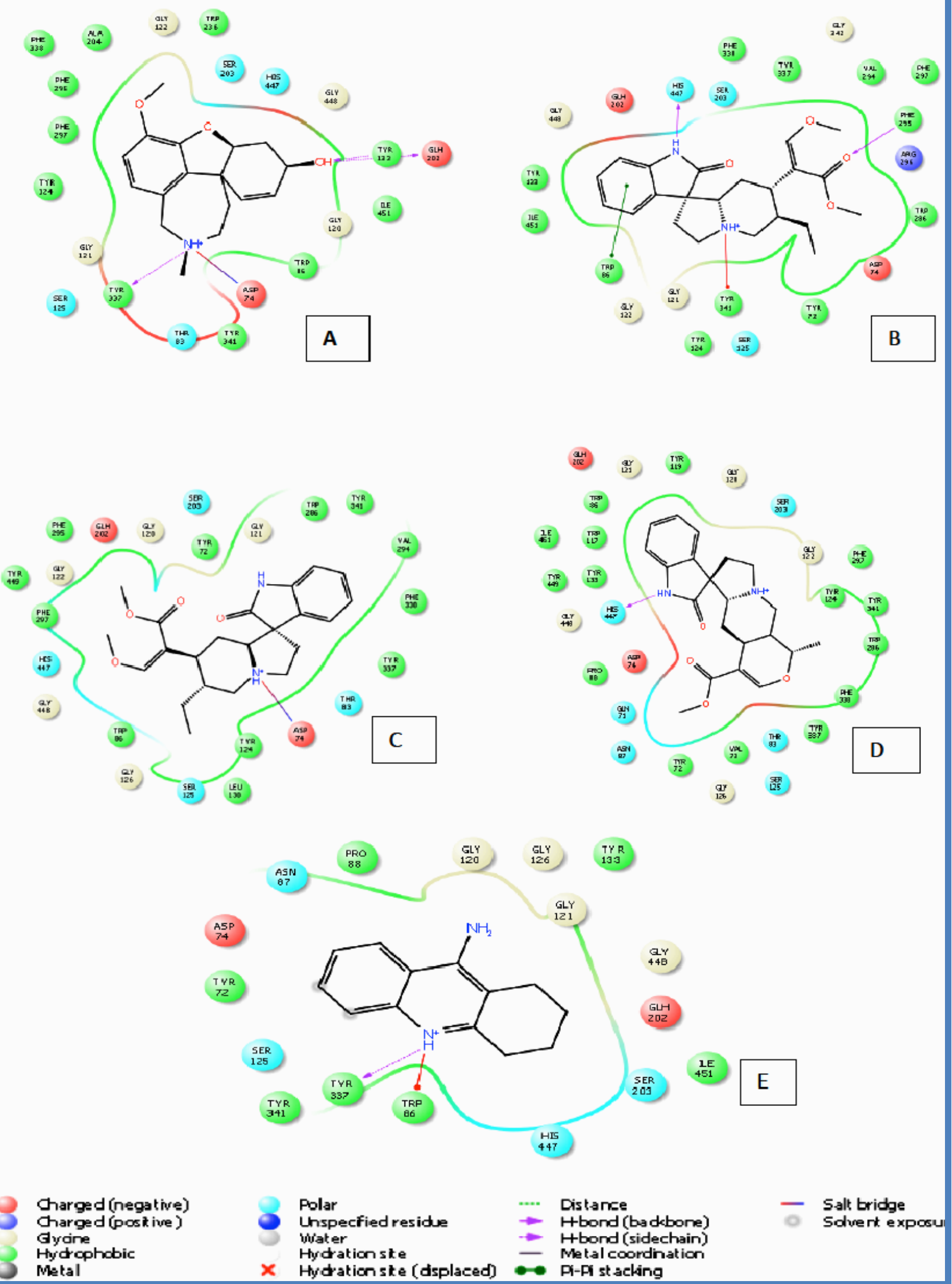

Figure 6: Ligprot representation of interaction between different residues of AChE enzyme and ligand (A - Galantamine, B Rhyncophylline, C - Isorhyncophylline, D - Unicarine E, E - Tacrine).

ISSN 0973-2063 (online) 0973-8894 (print) 
Table 1: Interactions in the docked complexes of ligands with AChE enzyme as obtained through Glide docking

\begin{tabular}{|c|c|c|c|c|c|c|}
\hline S. No & Ligand & $\begin{array}{l}\text { Glide score } \\
(\mathrm{Kcal} / \mathrm{mol})\end{array}$ & $\begin{array}{l}\text { Glide Energy } \\
\text { (Kcal/mol) }\end{array}$ & No. H-bonds & Interacting residues & Bond length $(\AA)$ \\
\hline & POSITIIVE CONTROL & & & & & \\
\hline 1 & Tacrine & -6.99 & -29.770 & 1 & Tyr337 & 2.56 \\
\hline \multirow[t]{3}{*}{2} & Galantamine & -10.98 & -43.850 & 3 & Tyr133 & 2.01 \\
\hline & & & & & Tyr337 & 2.05 \\
\hline & PHYTOCONSTITUENTS & & & & & \\
\hline 1 & Isorhynchophylline & -10.05 & -27.436 & 0 & - & - \\
\hline & & & & & Phe295 - Trp86 $(\pi-\pi)$ & 2.52 \\
\hline 2 & Uncarine E & -9.50 & -32.934 & - & - & - \\
\hline 3 & Rhynchophylline & -9.05 & -12.399 & 2 & His447 & 1.92 \\
\hline 4 & Uncarine $\mathrm{C}$ & -7.20 & -20.377 & & Tyr337- Tyr341 $(\pi-\pi)$ & \\
\hline 5 & Pteropodine & -7.07 & -29.155 & 1 & His447 & 2.62 \\
\hline 6 & Uncarine $\mathrm{F}$ & -6.91 & -29.116 & 1 & His447 & 2.49 \\
\hline \multirow[t]{2}{*}{7} & Speciophylline & -6.68 & -32.934 & 2 & Tyr337, & 2.02 \\
\hline & & & & & Thr83 & 2.79 \\
\hline 8 & Mitraphylline & -6.00 & -28.040 & 0 & - & - \\
\hline 9 & Isomitraphylline & -6.16 & -29.606 & 2 & $\begin{array}{c}\text { Tyr337, } \\
\text { His447 - Tyr337 }(\pi-\pi)\end{array}$ & 2.42 \\
\hline 10 & Isopteropodine & -5.96 & -19.107 & 0 & - & - \\
\hline
\end{tabular}

\section{Preparation of protein target structure}

Acetylcholinesterase complexed with (-)-Galantamine (PDBID4EY6, resolution $2.4 \AA$ ) was retrieved from the Protein Data Bank and further modified for Schrodinger's Glide docking calculations. For Glide v6.9 calculations, pdb file was imported to Maestro v10.4 and the protein was prepared using Protein Preparation Wizard (PPW) (Figure 1). All the water molecules were deleted except the seven water molecules, which were directly interacting with the important residues of the active site. Active site was defined using the (-)-Galantamine (inhibitor) from co-crystallized structure. The docking protocol was optimized by generating same crystal binding conformation of (-)-Galantamine with a root mean square deviation (RMSD) of $0.1273 \AA$ [19].

\section{Preparation of ligands}

3-D structures of $U$. tomentosa active constituents in .sdf format were retrieved from Pubchem database (Figure 2). LigPrep module of Schrodinger was used for ligand preparation [20].

\section{Ligand docking}

Prepared protein and ligands was docked using Glide (Gridbased Ligand Docking with Energetics) v6.9 module in Schrodinger. Extra precision module of Glide algorithm was used to dock ligand to the active site. All the Glide docking runs were performed on Intel® ${ }^{\circledR}$ Core $^{\mathrm{TM}}$ i7-3770 CPU @ $3.40 \mathrm{GHz}$ of HP origin, with 4GB RAM, Windows 8Pro operating system. The output from Glide was studied in XP visualizer and images were taken to study the interaction.

\section{Results \& Discussion:}

\section{Enzymatic inhibition study}

An aqueous extract of $U$. tomentosa plant inhibited AChE in a concentration dependent manner $(0.4$ to $0.02 \mathrm{mg} / \mathrm{ml})$. The aqueous extract showed maximum inhibition of enzyme ISSN 0973-2063 (online) 0973-8894 (print)
$(76.2 \pm 0.002 \%)$ at $0.4 \mathrm{mg} / \mathrm{ml}$ final concentration. The $\mathrm{IC}_{50}$ value obtained from inhibition curve was $0.112 \mathrm{mg} / \mathrm{ml}$ (Figure 3).

\section{Kinetic study}

The Lineweaver-Burk (LB) plot was used to study enzyme inhibition kinetics. The mode of inhibition displayed by LB plot was mixed inhibition (Figure 4). At the lower concentrations of an extract the plot suggested uncompetitive inhibition and at higher concentrations of extract showed non-competitive mode of inhibition. Hence, overall conclusion drawn from LB plot was mixed type of inhibition. The mixed mode of inhibition is very common in traditional medicinal plants due to the presence of different type of compounds in the extract [21]. Previous studies have suggested that for AChE induced betaamyloid aggregation can be overcome by mixed or non competitive mode of inhibition, as these inhibitors bind to the peripheral anionic sites and therefore inhibiting beta-amyloid accumulation and aggregation [22]. Apart from antioxidant, anti-inflammatory and immunomodulatory properties $U$. tomentosa has shown to potential action on beta-amyloid plaque formation.

\section{Molecular docking study}

For the selected 10 phytoconstituents 27 poses were generated after ligprep, out of which the poses with better glide score and lower glide energy for each ligand was selected. Analysis of molecular docking result showed that all the phytoconstituents have their Glide score in the range of -10.5 to $-5.96 \mathrm{Kcal} / \mathrm{mol}$ and Glide energy -32.934 to $-12.399 \mathrm{Kcal} / \mathrm{mol}$. Isorhynchophylline, Rhynchophylline and Unicarine E showed the best Glide score of $-10.05,-9.05$ and $-9.50 \mathrm{Kcal} / \mathrm{mol}$ respectively. When compared with Tacrine $(-6.99 \mathrm{Kcal} / \mathrm{mol})$, all the phytoconstituents showed more and comparable Glide score except Isopteropodine, Mitraphylline and Isomitraphylline. Although, previous studies shows significant 
binding of Mitraphylline to beta-amyloid (1-40) here it shows lower Glide score $(-6.00 \mathrm{Kcal} / \mathrm{mol})$. It was also observed that only Isorhynchophyllin showed Glide score as good as standard drug Galantamine, followed by Rhynchophylline. Among, the top three phytoconstituents on the basis of Glide score, Uncarine $\mathrm{E}$ has the lowest Glide energy (-32.934 $\mathrm{Kcal} / \mathrm{mol}$ ) and no hydrogen bonding interaction. While, Rhynchophylline with $-12.399 \mathrm{Kcal} / \mathrm{mol}$ of Glide energy, shows two hydrogen bonding interaction with residues His447 $(1.92 \AA$ bond length) and Phe295 (2.52 $\AA$ ) and one pi-pi interaction with Trp86. Whereas, Isorhynchophylline with Glide energy of $27.436 \mathrm{Kcal} / \mathrm{mol}$ shows no hydrogen bonding interaction (Figures 5 \& 6). To sum up all the phytoconstituents of $U$. tomentosa more or less shows a good binding affinity towards the active site of the acetylcholinesterase, on the basis of Glide score and Glide energy (Table1).

\section{Conclusion:}

$U$. tomentosa is an interesting herb in terms of its potential use in the treatment of AD. Previous in-vitro study showed that $U$. tomentosa extract prevents beta-amyloid plaque formation and in in-vivo improves memory function in mice. Our study revealed that an aqueous extract of $U$. tomentosa exhibits potent anti-AChE activity might be due to the presence of active constituent's oxindol alkaloids. Kinetic studies have indicated that an aqueous extract showed mixed mode of inhibition due to the presence of other phytoconstituents, which need further analysis. Above finding was validated with molecular docking study of its active constituents. Out of all the alkaloids Isorhynchophylline, Rhynchophylline and Unicarine E showed highest Glide score and lowest Glide energy as good as that of Galantamine the standard drug approved by food and Drug Administration (FDA). Moreover, U.Tomentosa antioxidant, antiinflammatory, immuno-modulatory, anti AChE and potential amyloid plaque prevention properties may have combined benefits for the treatment of AD. These findings add to a body of evidence suggesting further evaluation of the effect of aqueous extracts of $U$. tomentosa and its constituents.

\section{References:}

[1] Prince M et al. World Alzheimer Report. 2013

[2] Alzheimer's Association. Alzheimers Dement. 2015 11: 332 [PMID: 25984581]

[3] Rabins PV et al. Practical dementia care. Oxford University Press. 2006

[4] Nelson PT et al. J neuropathol exp neurol. 2012 71: 362 [PMID: 22487856]

[5] Kar S et al. J Psychiatry Neurosci. 2004 29: 427 [PMID: 15644984]

[6] Irvine GB et al. Mol Med. 2008 14: 451 [PMID: 18368143]

[7] Pohanka M, Int J Mol Sci. 2014 15: 9809 [PMID: 24893223]

[8] Kratky M et al. Bioorg Chem. 2015 58: 48 [PMID: 25462625]

[9] Chowdhury S et al. Anc Sci Life.. 2014 2: 64 [PMID: 25861138]

[10] Gurrola-diaz CM et al. Phytomedicine. 2011 18: 683 [PMID: 21156346]

[11] Heitzman ME et al. Phytochemistry. 2005 66: 5 [PMID: 15649507]

[12] Pilarski R et al. J ethnopharmacol. 2006 104: 18 [PMID: 16202551]

[13] Mohamed AF et al. J Pharm Pharmacol. 2000 52: 1553 [PMID: 11197086]

[14] Castillo G et al. U.S. Patent No. 6264994. 2001

[15] Fr ckowiak T et al. Z Naturforsch C. 2006 61: 821 [PMID: 17294693]

[16] Kozielewicz P et al. Monatshefte für Chemie. 2014 145: 1201

[17] Yunis Anguinaga J et al. J toxicol. 2014 6: 5

[18] Ellman GL et al. Biochem Pharmacol. 1961 7: 88 [PMID: 13726518]

[19] Small-Molecule Drug Discovery Suite 2015-4: Glide, version 6.9, Schrödinger, LLC, New York, NY, 2015.

[20] Schrödinger Release 2015-4: LigPrep, version 3.6, Schrödinger, LLC, New York, NY, 2015.

[21] Bartolini M et al. Biochem Pharmacol. 2003 65: 407 [PMID: 12527333]

[22] Kumar S \& Chowdhury S, Pharmaceutical and Biological Evaluations. 2015 2: 25

Edited by $P$ Kangueane

Citation: Chowdhury et al. Bioinformation 12(3): 112-118 (2016) License statement: This is an Open Access article which permits unrestricted use, distribution, and reproduction in any medium, provided the original work is properly credited. This is distributed under the terms of the Creative Commons Attribution License

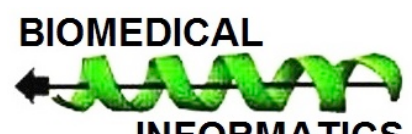

INFORMATICS 